\title{
How are healthcare institutions using Facebook to interact with online communities? Results from a case study in Central Pennsylvania
}

\author{
Daniel R. George ${ }^{* 1}$, Lauren Kime ${ }^{2}$, Timothy D. Riley ${ }^{3}$ \\ ${ }^{1}$ Department of Humanities, Penn State Hershey College of Medicine, Hershey, PA, United States \\ ${ }^{2}$ George T. Harrell Health Sciences Library, Penn State Hershey College of Medicine, Hershey, PA, United States \\ ${ }^{3}$ Department of Family and Community Medicine, Penn State Milton S. Hershey Medical Center, Hershey, PA, United States
}

Received: April 12, 2015

DOI: $10.5430 /$ jha.v4n3p89
Accepted: May 14, 2015

Online Published: May 21, 2015

\begin{abstract}
Social media tools and applications are increasingly being integrated into modern medicine. However, little is known about how healthcare institutions are interacting online with their populations. In this case study, we identified a convenience sample of 11 institutions in Central Pennsylvania with Facebook Pages and evaluated their interactions with online communities. From May-June 2013, we noted type of healthcare institution (e.g. hospital, family practice); number of overall "likes" accrued by the healthcare facility; number of overall posts and "likes", "comments", and "content shares" associated with those posts; as well as number of location check-ins by "followers". We thematically categorized each institutional post. Average number of Facebook Page "likes" was 2,261, and average number of overall posts was 28.9, or about one post every three days. On average, each post generated 16 "likes", 1 comment, and 2.4 shares. Average number of location "check-ins" by visiting patients was 6,348. Most commonly published content across all Pages was advertisements (89\%) and institutional news (89\%). Patient populations in Central Pennsylvania are seeking out healthcare institutions on Facebook, although most communication appears unidirectional and involves institutional advertising and promotion. There are opportunities for institutions to focus on health promotion and undertake "social" preventive health strategies using social media.
\end{abstract}

Key Words: Technology assessment, Social media, Health promotion, Health education, Population health

\section{INTRODUCTION}

Social media tools and applications encompassing blogs, social networks, video- and photo-sharing sites, wikis, and other media that enable real-time publishing of user content, have shown the potential to impact human behavior on a global scale. From their role in facilitating recent civil uprisings to serving as the infrastructure for "viral" fundraising efforts for Ebola and ALS, popular social media sites like Facebook (which has exceeded one billion users ${ }^{[1]}$ ) and Twitter have demonstrated a capacity to shape and influence world events.

Even in contemporary medicine, a profession predicated on privacy, confidentiality, and the sanctity of one-on-one relationships, social media have presented opportunities for healthcare professionals to expand reach with patients and increase public access to credible, science-based health mes-

\footnotetext{
*Correspondence: Daniel R. George; Email: dgeorge1@ @mc.psyu.edu; Address: Department of Humanities, 500 University Drive, Hershey, PA 17033, United States.
} 
sages. ${ }^{[2]}$ Recent estimates of social media usage by doctors has risen from $41 \%$ in 2010 to $90 \%$ in 2011 , while rates of use have been found to be above $90 \%$ for medical students, implying that future medical professionals may be more likely to integrate social media into their practice. ${ }^{[3-5]}$ Furthermore, a growing number of patients - particularly those with chronic conditions - are seeking out social media and other online sources to acquire health information, connect with others affected by similar conditions, and play a more active role in their healthcare decisions. ${ }^{[6-8]}$ Research has established that hospitals are increasingly integrating social media technology, and that Facebook Pages have been adopted by $94 \%$ of institutions in the US. ${ }^{[9]}$

Despite this well-documented expansion of social media at all levels of medicine, little is known about how healthcare institutions are presently using social networking technologies such as Facebook to interact with the populations they serve. ${ }^{[10]}$ The goal of this case study was to select a convenience sample of healthcare institutions in one discreet region (Central Pennsylvania) and examine how they interacted with online communities via Facebook Pages.

\section{Methods}

We used Google Maps to identify a comprehensive sample $(\mathrm{n}=50)$ of hospitals and family practice/general medicine sites in Dauphin, Lebanon, and Lancaster counties in Central Pennsylvania. These three counties include a mix of rural and urban populations, with a total of 921,113 inhabitants. ${ }^{[1]}$ We then used Facebook's search function to identify whether each identified institution actively maintained a "Page" - an online community Facebook has designed to serve as the official profile for entities, such as celebrities, brands or businesses. All institutions that had devoted Pages were included in the study.

Between May and July 2013, we observed all active Pages, creating a spreadsheet to note the type of healthcare institution (e.g. family practice clinics, hospitals, academic medical centers); number of overall Page "likes" accrued by the healthcare facility by July 2013; number of overall posts and the "likes", "comments", and "content shares" (i.e. users re-posting content to their pages) associated with particular posts; as well as the number of location check-ins by "followers" (a process through which users can share their current geographic location with friends in their network). We also noted: (1) whether the Pages permitted the posting of user content (or whether this was limited to site administrators), (2) whether Pages linked to other social media sites associated with the clinic (i.e. YouTube, Twitter, Pinterest pages), and (3) whether information from external websites was shared. Further, we thematically categorized each insti- tutional post during the 3-month period into eleven potential content types: advertisements, age-specific postings (e.g. for retirees over 65), disease or condition-specific advice, disease or condition awareness or prevention, fundraising, health education, health topics in the news, institutional events, institutional news, population-specific postings (e.g. cancer survivors), and study recruitment. We used descriptive statistics to provide a quantitative overview of our findings. Due to the public nature of the social media postings and interactions, this study did not fall under the purview of an institutional review board.

\section{RESUlTS}

Out of the initial list of 50 healthcare facilities, 11 were confirmed as having active Facebook Pages. Six Pages were family practice clinics with fewer than 15 physicians or advanced practice providers; four were hospitals, and one was an academic health center. One small family practice was excluded due to no content being published during the 3-month time frame for data collection study interval.

Across all Pages, average number of overall "likes" from the population was 2,261. Over the three-month interval, the average number of overall posts was 28.9 , or about one post every three days. On average, each post generated 16 "likes", 1 comment, and 2.4 shares. The average number of location "check-ins" by visiting patients was 6,348 . Six of the Pages permitted the posting of user content on their "wall" while the other five limited posting privileges to approved site administrators. Three Pages linked to other forms of social media associated with the clinic, and 50\% shared information from external websites.

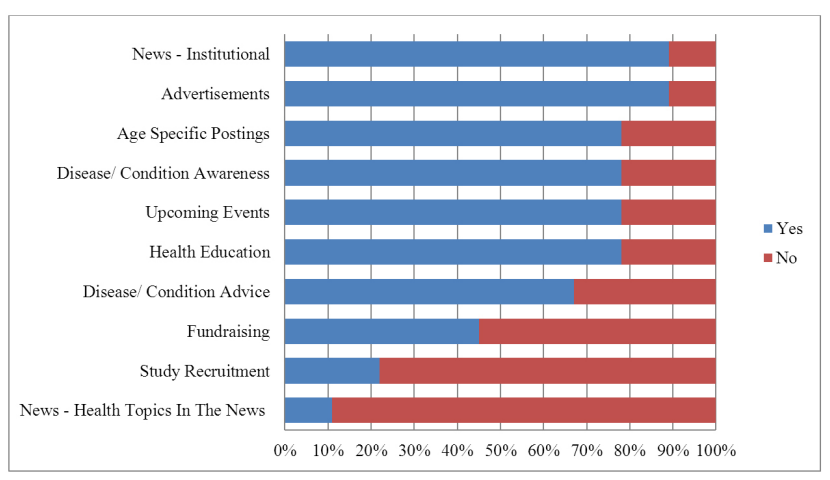

Figure 1. Appearance of themes on healthcare institution Facebook Pages

With regard to thematic content, the type of post most commonly published across all Pages was advertisements (89\%) and institutional news (89\%), followed by information on health education (78\%), postings about institutional 
events (78\%), age-specific postings targeting specific populations $(78 \%)$, disease or condition awareness or prevention $(78 \%)$, disease or condition-specific advice (67\%), fundraising $(45 \%)$, study recruitment $(22 \%)$, and health topics in the news (11\%) (see Figure 1).

\section{Discussion}

From our convenience sample, it appears a substantial number of community members are seeking out their healthcare institutions online on Facebook, although there is perhaps less active engagement than one might expect on a popular social networking platform. Specifically, while simpler forms of engagement (i.e. liking or sharing content) were frequent, there were fewer indications of deeper engagement through commenting and discussion. Most communication between healthcare institutions and patients thus appears from our sample to be unidirectional.

Another major finding is that healthcare institutions in our sample appeared to be almost uniformly using their Facebook Pages to advertise and post institutional news. Thus, there appears to be greater opportunity to move beyond institutional self-promotion and more robustly share health education content with Facebook users, as well as to use Pages as a means of recruiting for research studies, disseminating health topics in the news, or facilitating conversation with and between patients to promote beneficial health practices with "viral" potential (e.g. weight loss initiatives, walking or cycling groups, and support groups). By taking a more active educational role and leveraging the networking effect of these technologies, institutions could deepen patient awareness of public health issues and foster opportunities for patients to pose questions, gain a more nuanced understanding of how to care for themselves and their families, or feel greater affinity with the medical community. Drawbacks to increased engagement might include an increase in controversial or offensive responses from patients, or less professionalism and difficulty maintaining professional boundaries between patients and professionals (healthcare or otherwise) who might post content on an institutional Facebook Page, and potential litigation. ${ }^{[12]}$ Ethical implications regarding patient privacy are also of potential concern, as social media sites are a platform on which users commonly share detailed and personal information. ${ }^{[13]}$

This study was limited to a convenience sample of healthcare institutions in one region of Pennsylvania, and thus the generalizability of our results is unclear. We also only noted the appearance of themes during a 3-month interval rather than analyzing the frequency of those themes on each Page. Furthermore, data collected in our study reflect the specific functionality of Facebook and related applications during a discreet period of time (2013). Future research might engage a larger or more regionally diverse sampling of medical institutions, and might follow a cohort over a longer interval of time. ${ }^{[14]}$ It would also be useful to qualitatively document best practices undertaken by medical institutions that are successfully engaging the people they serve, and to identify meaningful outcomes that might become benchmarks for other efforts.

Given recent changes in US healthcare policy ushered in by passage of the Affordable Care Act, there is greater relative emphasis being placed on extending care into the community, communicating better with patients and families, and fostering team-based preventive care. ${ }^{[15]}$ Further, national trends away from fee-for-service ${ }^{[16]}$ may enable private practices to devote more resources for outreach to their patients through platforms such as social media. These changes in the healthcare environment should at the very least engender reflection on how social media such as Facebook - which provide unprecedented opportunities for cost-effective, one-to-many communication between institutions, health professionals and patients - can be most effectively integrated into current and future medical practice to contribute to public health.

\section{REFERENCES}

[1] George DR, Rovniak LS, Kraschnewski JL. Dangers and opportunities for social media in medicine. Clinical Obstetrics of Gynecology. 2013; 56(3): 453-62. PMid: 23903375. http://dx.doi.org/10. 1097/GRF.0b013e318297dc38

[2] Centers for Disease Control and Prevention. The Health Communicator's Social Media Kit. 2011. Available from: http://www.cdc.gov/socialmedia/tools/guidelines/p $\mathrm{df} /$ socialmediatoolkit_bm.pdf. Accessed October 12, 2013.

[3] Bosslet GT, Torke AM, Hickman SE, et al. The patient-doctor relationship and online social networks: results of a national survey. Journal of General Internal Medicine. 2011; 26(10): 1168-
74. PMid: 21706268. http://dx.doi.org/10.1007/s11606-0 11-1761-2

[4] Modahl M, Tompsett L, Moorhead T. Doctors, Patients \& Social Media. 2011. Available from: http://www . quantiamd.com/q-q $\mathrm{cp} /$ DoctorsPatientSocialMedia.pdf. Accessed January 15, 2013.

[5] George DR, Green M, Navarro A, et al. Social media in medicine re-examined: results from a national survey on medical students' use of Facebook and other social networking technologies. American Journal of Bioethics Research. 2014; 5(2): 68-79.

[6] The Social Life of Health Information. 2009 Pew Internet \& American Life Project. Available from: 
http://www pewinternet.org/files/old-media/Fil es/Reports/2009/PIP_Health_2009.pdf. Accessed March, 2012.

[7] Hale TM, Pathipati AS, Zan S, et al. Representation of health conditions on Facebook: content analysis and evaluation of user engagement. Journal of Medical Internet Research. 2014; 16(8): e182. http://dx.doi.org/10.2196/jmir.3275

[8] Shrank WH, Choudhry NK, Swanton K, et al. Variations in structure and content in online social networks for patients with diabetes. Archives of Internal Medicine. 2011; 171(17): 1589-91. PMid: 21949173. http://dx.doi.org/10.1001/archinternm ed. 2011.407

[9] Griffis HM, Kilaru AS, Werner RM, et al. Use of Social Media Across US Hospitals: Descriptive Analysis of Adoption and Utilization. Journal of Medical Internet Research. 2014; 16(11): e264. PMid: 25431831. http://dx.doi.org/10.2196/jmir. 3758

[10] Neiger BL, Thackeray R, Van Wagenen SA, et al. Use of social media in health promotion: purposes, key performance indicators, and evaluation metrics. Health Promotions \& Practice. 2012; 13(2): 159-64. PMid: 22382491. http://dx.doi.org/10.1177/15248 39911433467

[11] U.S. Census Bureau, 2010 Census of Population: State \& County QuickFacts. Available from: http://quickfacts.census.gov/ qfd/index.html. Accessed May 24, 2014.
[12] American Medical Association. AMA Policy: Professionalism in the Use of Social Media. Available from: http: //www .ama-assn.org/ama/pub/physician-resources/med ical-ethics/code-medical-ethics/opinion9124.page. Accessed February 3, 2014.

[13] McKee R. Ethical issues in using social media for health and health care research. Health Policy. 2013; 110(2-3): 298-301. PMid: 23477806. http://dx.doi.org/10.1016/j.healthpol.2013. 02.006

[14] Grajales FJ, Sheps S, Ho K, et al. Social Media: A Review and Tutorial of Applications in Medicine and Health Care. Journal of Medical Internet Research. 2014; 16(2): e13. PMid: 24518354. http://dx.doi.org/10.2196/jmir. 2912

[15] Barnes KA, Kroening-Roche JC, Comfort BW. The developing vision of primary care. New England Journal of Medicine. 2012; 367(10): 891-3. PMid: 22931258. http://dx.doi.org/10.1056/NEJMp 1204487

[16] Millman J. The Obama administration wants to dramatically change how doctors are paid. Washington Post. 2015 Jan 26. Available from: http ://www . washingtonpost . com/blogs/wonkblog/wp/201 5/01/26/the-obama-administration-wants-to-dramati cally-change-how-doctors-are-paid/. Accessed March 30, 2015. 